\title{
Neuroendocrine control of reduced persistence of egg- laying in domestic hens: evidence for the development of photorefractoriness
}

\author{
P. J. Sharp ${ }^{1}$, I. C. Dunn ${ }^{1}$ and S. Cerolini ${ }^{2}$ \\ 'AFRC Institute of Animal Physiology and Genetics Research, Edinburgh Research Station, Roslin, \\ Midlothian EH25 9PS, UK; and ${ }^{2}$ Department of Veterinary Medicine, University of Milan, 20133 \\ Milan, Italy
}

\begin{abstract}
Summary. Egg-laying in hens exposed for more than 11 months to photostimulatory daylengths was intermittent and associated with a reduction in numbers of yellowyolky ovarian follicles. Old laying hens (105 weeks) had lower concentrations of luteinizing hormone $(\mathrm{LH})$ in the pituitary gland and plasma and reduced pituitary gland responsiveness to chicken LH-releasing-hormones (LHRH-I and II) in vivo when compared with young laying hens ( 28 weeks). Four weeks after transfer from 14 to $8 \mathrm{~h}$ light/day, egg production almost stopped in old, but not in young hens, although plasma LH concentrations decreased in all birds. After transfer from 14 to $20 \mathrm{~h}$ light/day, plasma LH increased in young, but not in old, hens, without a change in the rate of egg production. Reproductive function was enhanced in old hens returned to long days after induction of a moult and ovarian regression by reducing daylength and dietary restriction. Moulted hens had a greater rate of egg production, higher concentrations of plasma LH and a greater pituitary-gland responsiveness to LHRH-II in vivo than unmoulted control hens. After transfer from 14 to $8 \mathrm{~h}$ light/day, egg-laying decreased more rapidly in unmoulted than in moulted hens; transfer to $17 \mathrm{~h} \mathrm{light/day}$ increased egg production in moulted, but not in unmoulted, birds. Induction of ovarian regression in old hens by dietary restriction alone also enhanced reproductive function after the dietary restriction was relaxed. Egg-laying was more persistent in hens brought into lay for a second year by transferring them from 3 to $11 \mathrm{~h} \mathrm{light/day} \mathrm{than}$ in hens transferred from 3 to $20 \mathrm{~h}$ light/day. Egg production was stimulated in hens maintained on 3 or $11 \mathrm{~h} \mathrm{light/day} \mathrm{for} 42$ weeks, after transfer to $20 \mathrm{~h} \mathrm{light/day.} \mathrm{Egg}$ production ceased in hens maintained on $20 \mathrm{~h} \mathrm{light/day} \mathrm{for} 46$ weeks, after transfer to $3 \mathrm{~h} \mathrm{light/day.}$

These observations are consistent with the view that poor persistence of laying in hens $<2$ years old and exposed continuously to long days is caused, in part, by a reduction in hypothalamic-gonadotroph function. This reduction in neuroendocrine function may be due, in part, to the development of relative photorefractoriness.
\end{abstract}

Kelutords: ovary; ageing; chicken: LH: egg-laying: seasonal breeding; photorefractoriness

\section{Introduction}

Domestic hens become somatically mature at $18-22$ weeks. Transfer from short to long days at this age stimulates and synchronizes a rapid onset of egg-laying which is sustained at a high rate for several weeks. Thereafter, the rate of egg-laying falls progressively in association with a reduction in recruitment of ovarian follicles into the yellow-yolky follicular hierarchy (Williams \& Sharp, 1978a; Zakaria et al., 1983; Waddington et al., 1985). It is possible that this decreased persistence of 
egg-laying is caused by a reduction in the release of gonadotrophin-releasing hormone $(\mathrm{GnRH})$ from the hypothalamus and reduced gonadotrophin secretion. In support of this view, a reduction in base-line concentrations in plasma luteinizing hormone $(\mathrm{LH})$ has been observed to be associated with reduced egg-laying (Williams \& Sharp, 1978b; Tanabe et al., 1981). A reduction in GnRH release associated with reduced persistence of egg-laying after prolonged exposure to stimulatory daylengths could be due to the development of photorefractoriness (review, Nicholls et al., 1988). In hens exposed to natural daylengths, egg production falls in autumn before daylength decreases below the minimum required to stimulate egg-laying in the spring (Whetham, 1933; review, Sharp, 1984). This autumnal decrease appears not to be due to age per se, because egg production returns to high rates after exposure to the short days of winter and increasing daylengths in spring (Brody et al., 1938). Egg production during successive years only begins to decrease markedly in hens which are more than 4 years old (Brody et al., 1938). It therefore appears that autumnal photorefractoriness is dissipated by the short days of winter, as has been observed for various passerine species (review, Nicholls et al., 1988).

The object of this study was to establish whether the reduction in persistence of laying in hens less than 2 years old and exposed continuously to long daylengths is associated with reduced hypothalamic-gonadotroph function and, if so, whether this is due to the development of relative photorefractoriness.

\section{Materials and Methods}

\section{Hens}

Dwarf broiler breeder hens (Ross Breeders Ltd, Newbridge, Lothian, UK) were obtained at 1 day old and reared on the floor under $8 \mathrm{~h}$ light/day. At 19-21 weeks they were caged individually and daylength was increased to 14 or $16 \mathrm{~h}$ to stimulate and synchronize the onset of egg production. The laying hens were fed a restricted layers' diet $(115 \mathrm{~g} / \mathrm{hen} / \mathrm{day})$ to prevent excessive deposition of fat, as recommended by the suppliers. Records were kept of the number of eggs laid by each hen on each day.

\section{Hypothalamic-pituitary-gland-ovarian function in ageing hens}

Egg production and the hypothalamic-pituitary-gland-ovarian axis. An initial study was carried out to establish the pattern of egg production associated with reduced persistence of laying during a first laying year. Changes in weights of oviducts and ovaries and anterior pituitary glands, numbers of ovarian follicles, content of pituitary $\mathrm{LH}$ and hypothalamic LHRH-I and concentrations of plasma LH were recorded.

Pituitary gland responsiveness to $\mathbf{L H R H - I}$ and $I I$. Responsiveness was assessed in vivo in young (28 weeks) and old (I05 weeks) laying hens. Chicken LHRH-I and II (Penninsula Laboratories, Europe Ltd, St Helens, Merseyside, UK) were dissolved in physiological saline and injected intravenously into a wing vein. Blood samples $(1 \mathrm{ml})$ were taken from the contralateral wing vein immediately before and $5,10,20,40$ and $60 \mathrm{~min}$ after injection. The doses of LHRHI and II used were selected to lie on a dose response curve as described by Sharp et al. (1987). Only one dose of LHRH-I was used $(20 \mu \mathrm{g} / \mathrm{kg})$ because, in preliminary studies, doses of 5 or $10 \mu \mathrm{g} / \mathrm{kg}$ did not stimulate LH release whereas 20 and $50 \mu \mathrm{g} / \mathrm{kg}$ were equally effective (I. C. Dunn \& P. J. Sharp, unpublished observations).

Eight hens were each given all doses of LHRH-I and II and saline vehicle on successive days $4 \mathrm{~h}$ before the end of the light period to avoid pre-ovulatory releases of LH (Sharp, 1983), using a Latin-square design.

Changes in photoperiodic responses. The possibility that reduced persistence of lay may be caused by reduced hypothalamic-pituitary-gland function was investigated by comparing the photoperiodic responses of young and old laying hens held on a stimulatory daylength ( $14 \mathrm{~h} \mathrm{light/day)} \mathrm{to} \mathrm{a} \mathrm{further} \mathrm{increase} \mathrm{in} \mathrm{daylength} \mathrm{(} 20 \mathrm{~h} \mathrm{light/day)} \mathrm{or} \mathrm{to}$ transfer to short daylengths $(8 \mathrm{~h}$ light/day). The prediction was that reduced hypothalamic-pituitary-gland function would result in a more rapid decrease in reproductive function in old than in young hens after the removal of the stimulatory effects of long days. Conversely, after an increase in daylength, it was predicted that hypothalamicpituitary-gland function would be stimulated more in young than in old hens.

\section{Studies to demonstrate the development of photorefractoriness and its effect on egg-laying}

Three studies were carried out to establish whether reduced egg-laying was due to the development of photorefractoriness. 
Effect of short-day treatment combined with dietary restriction and return to long days. The first study was based on the observation that exposure of photorefractory birds to short days results in the dissipation of photorefractoriness and the recovery of photosensitivity (Nicholls et al., 1988). It was predicted that transfer of old hens, with a poor rate of egg production, from long ( $14 \mathrm{~h} \mathrm{light/day)} \mathrm{to} \mathrm{short} \mathrm{days} \mathrm{(} 3 \mathrm{~h}$ light/day) for 6 weeks would result in a recovery of photosensitivity and, hence, increased hypothalamic-pituitary-gland-ovarian function after return to long days. To ensure that egg production ceased entirely after transfer to short days, the hens were also given less food, following the procedure recommended by the Ministry of Agriculture, Food and Fisheries (MAFF; Wakeling, 1985) to induce a moult. This involved feeding the birds $15 \mathrm{~g}$ whole oats/day until body weight decreased by $25 \%$. Thereafter, the hens were fed $40 \mathrm{~g}$ broiler finisher diet/day until Day 40 of treatment when they were returned to the original lighting and feeding conditions. Hypothalamic-pituitary-gland ovarian function was compared in moulted and unmoulted control hens by measuring pituitary and plasma LH. LH responsiveness to cLHRH-II in vivo and changes in egg production and plasma $\mathrm{LH}$ concentration after increasing daylength to $11 \mathrm{or} 17 \mathrm{~h} \mathrm{light/day} \mathrm{or} \mathrm{decreasing} \mathrm{daylength} \mathrm{to}$ 8 h light day.

Comparison of effects of induction of ovarian regression by short-day treatment or dietary restriction. The second study on the development of photorefractoriness was carried out to establish whether recovery of hypothalamicpituitary-gland function in the first study was due to the short-day treatment alone or to dietary restriction. Accordingly, groups of old hens exposed to $14 \mathrm{~h} \mathrm{light/day} \mathrm{with} \mathrm{records} \mathrm{of} \mathrm{poor} \mathrm{egg} \mathrm{production} \mathrm{were} \mathrm{transferred} \mathrm{to}$ continuous light for 14 weeks to enhance the putative development of photorefractoriness. Ovarian regression and associated moult were induced by reducing daylength or food intake for 40 days. The induction of moult by reducing food intake followed the procedure recommended by MAFF (Wakeling, 1985) except that the hens were maintained in continuous light. Rates of egg production, weights of ovaries and oviducts and concentrations of plasma LH were then compared after increasing the daylength or food intake.

Effect of daylength on persistence of egg laying. The final study on the development of photorefractoriness was based on the observation that photorefractory species can be brought into breeding condition, but do not develop photorefractoriness after transfer from short daylengths to days which are longer than, but close to, the minimum required for photoinduced gonadal growth (Nicholls et al., 1988). Since a marginally stimulatory daylength for domestic hens is 1I h (Sharp. 1988; Dunn \& Sharp, 1990), a comparison was made of egg production in out-of-lay photosensitive hens transferred from short days to photostimulatory daylengths of $20 \mathrm{or} 11 \mathrm{~h} \mathrm{light/day,} \mathrm{respectively.}$ The hens had previously been laying for a year and had then been transferred to $3 \mathrm{~h}$ light/day combined with food restriction at 74 weeks of age to induce a moult as recommended by MAFF (Wakeling, 1985). The prediction was that transfer to $20 \mathrm{~h} \mathrm{light/day} \mathrm{would} \mathrm{induce} \mathrm{the} \mathrm{development} \mathrm{of} \mathrm{photorefractoriness} \mathrm{resulting} \mathrm{in} \mathrm{reduced} \mathrm{persistence} \mathrm{of} \mathrm{lay,}$ whereas this effect would not be observed in hens transferred to $11 \mathrm{~h} \mathrm{light/day.} \mathrm{At} \mathrm{the} \mathrm{end} \mathrm{of} \mathrm{this} \mathrm{experiment,} \mathrm{the}$ functional state of the hypothalamic-gonadotroph axis in the three groups of hens was assessed by transferring hens

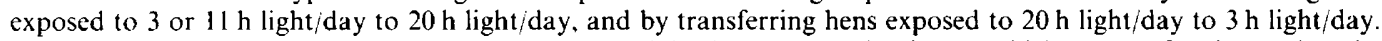
It was predicted that in hens exposed to 3 or $11 \mathrm{~h} \mathrm{light/day,} \mathrm{egg} \mathrm{production} \mathrm{would} \mathrm{increase} \mathrm{after} \mathrm{increasing} \mathrm{the}$ daylength. Conversely, it was predicted that hens exposed to $20 \mathrm{~h}$ light/day would be driven towards a photorefractory state and that removal of the stimulatory effects of long days would result in a rapid cessation of egg-laying.

\section{Collection of blood samples and tissues}

Blood samples $(1 \mathrm{ml})$ were taken by direct venepuncture from a wing vein and the plasma was stored at $-20^{\circ} \mathrm{C}$ prior to assay for LH. Hens were killed by cervical dislocation and yellow-yolky ovarian follicles $>8 \mathrm{~mm}$ in diameter were counted and removed before weighing the remainder of the ovary. The weights of the oviducts were also recorded. Hens with pathological conditions, such as ovarian carcinomas, were excluded from the study.

Hypothalami were dissected as described by Sharp et al. (1987), boiled for $10 \mathrm{~min}$ in $2 \mathrm{M}$ acetic acid and homogenized by sonication. After centrifugation, the supernatants were frozen in liquid nitrogen and then lyophilized. The lyophilized extracts were reconstituted in radioimmunoassay buffer $(1 \mathrm{ml})$ before assay for chicken LHRHI. Anterior pituitary glands were homogenized in $\mathrm{LH}$ radioimmunoassay buffer in glass homogenizers and stored at $-20 \mathrm{C}$ prior to assay.

\section{Hormone assays}

Plasma LH was measured as described by Sharp et al. (1987); the inter- and intra-assay coefficients of variation were 7 and $9 \%$, respectively. Hypothalamic chicken LHRH-I was measured as described by Lal et al. (1990); the interand intra-assay coefficients of variation were 5 and $4 \%$, respectively.

\section{Statistics}

Statistical analyses were carried out by standard analyses of variance and least-significant differences, Mann-Whitney $U$ test or Student's $t$ test as appropriate. The exception was for comparisons between number of hens laying in different treatment groups: these were made using Finney's $2 \times 2$ contingency tables. 


\section{Results}

\section{Changes in hypothalamic-pituitary-gland-ovarian function in ageing hens}

Egg production and associated changes in the hypothalamic-pituitary-gland-ovarian axis. Egg production in hens in their first laying year reached a peak of 5 eggs/hen/week at 29 weeks of age, 7 weeks after transfer from 8 to $14 \mathrm{~h}$ light/day (Fig. 1a). Thereafter, it fell progressively to $2-2.5$ eggs/hen/week at $\sim 60$ weeks. From $\sim 45$ weeks, the progressive decrease in egg production was associated with an increase in hens not laying for 1 week or more (Fig. la). An analysis of individual egg-laying records at the end of the first laying year, between 65 and 85 weeks, showed that $80 \%$ of the hens alternated between several weeks of laying and non-laying (Fig. $1 \mathrm{~b}$ ). The remaining hens ceased laying entirely or only laid erratically; on post-mortem examination, they were found to be ovulating internally or to have ovarian cancers.
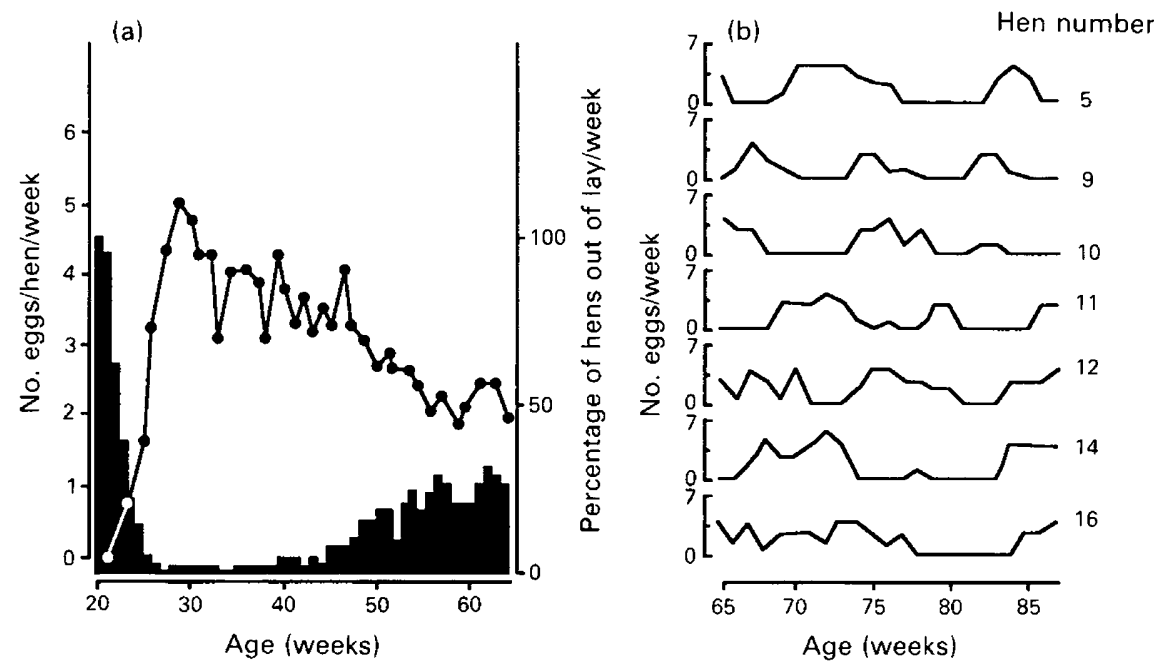

Fig. 1. Egg production in domestic hens (a) during their first laying year, showing no. eggs/hen/ week ( $)$ and, in the histogram, the percentage of hens out of lay/week $(n=37)$ and (b) in seven representative individuals at the end of their first laying year. The hens were reared on $8 \mathrm{~h}$ light/day and transferred to $14 \mathrm{~h}$ light/day at 18 weeks to stimulate and synchronize the onset of egg production.

Decreased egg production was associated with increased body weight, fewer yellow-yolky follicles in the ovary, decreased pituitary LH content and concentration, and reduced concentrations of plasma LH (Table 1). The pituitary glands and the ovaries, without yellow-yolky follicles, in old laying hens weighed more than in young laying hens, while there were no differences in the weights of oviducts (Table I). No differences were seen in hypothalamic LHRH-I content in young and old hens (Table 1).

Changes in pituitary-gland responsiveness to chicken $\mathbf{L H R H}-\mathbf{I}$ and $I I$. The concentrations of baseline plasma $\mathrm{LH}$ in young and old hens used to compare pituitary-gland responsiveness to chicken LHRH-I and II in vivo were $2.34 \pm 0.11$ and $1.40 \pm 0.12 \mathrm{ng} / \mathrm{ml}(n=8)$, respectively; they were significantly different $(P<0.01)$. In both young and old hens, the maximum increase in plasma LH in response to LHRH-I or II was observed 10-20 min after i.v. injection. The concentration of plasma LH increased in response to $0 \cdot 25,0 \cdot 5,1$ and $2 \mu \mathrm{g} \mathrm{LHRH}-\mathrm{II} / \mathrm{kg}$ and to $20 \mu \mathrm{g}$ LHRH-I/kg in both young and old laying hens (Fig. 2). Dose-response curves were not observed for LHRH-I in either young or old hens or for LHRH-II in old hens. A dose-response curve was obtained for LHRH-II in young hens (regression coefficient, $0.77 ; P<0.05$ ). 
Table 1. Weights of reproductive organs, concentrations of pituitary gland and plasma luteinizing hormone ( $\mathrm{LH})$, and content of hypothalamic LH-releasing hormone (LHRH-I) in young (28 weeks) and old ( 105 weeks) laying and non-laying hens (means \pm s.e., $n=8$ )

\begin{tabular}{|c|c|c|c|}
\hline & Young layers & Old layers & Old non-layers \\
\hline Body weight ( $g$ ) & $2059 \pm 59^{a}$ & $3155 \pm 113^{\mathrm{b}}$ & $2985 \pm 149^{\mathrm{b}}$ \\
\hline Egg production (no. of eggs/hen/week) & $5 \cdot 50 \pm 0 \cdot 19^{\mathrm{a}}$ & $2 \cdot 37 \pm 0.44^{b}$ & $\frac{1}{0}$ \\
\hline Pituitary weight (mg) & $7 \cdot 83 \pm 0.26^{\mathrm{a}}$ & $9 \cdot 60 \pm 0.35^{\mathrm{bc}}$ & $8.79 \pm 0.37^{\mathrm{ac}}$ \\
\hline Ovary weight without yellow-yolky follicles (g) & $6.33 \pm 0.45^{\mathrm{a}}$ & $8 \cdot 16 \pm 0.52^{\mathrm{b}}$ & $4.62 \pm 0.36^{\circ}$ \\
\hline Oviduct weight (g) & $52.84 \pm 1.79^{a}$ & $54 \cdot 26 \pm 4 \cdot 64^{\mathrm{a}}$ & $7 \cdot 35 \pm 1.33^{\mathrm{b}}$ \\
\hline No. of yellow-yolky follicles & $5 \cdot 50 \pm 0 \cdot 25^{\mathrm{a}}$ & $4.37 \pm 0.21^{\mathrm{b}}$ & $0.38 \pm 0.0 \mathrm{I}^{\mathrm{c}}$ \\
\hline Pituitary LH content ( $\mu \mathrm{g} /$ pituitary) & $9 \cdot 44 \pm 1 \cdot 23^{\mathrm{a}}$ & $4.85 \pm 0.61^{\mathrm{b}}$ & $4.65 \pm 0.54^{\mathrm{b}}$ \\
\hline Pituitary LH concentration $(\mu \mathrm{g} / \mathrm{mg})$ & $1 \cdot 20 \pm 0 \cdot 14^{\mathrm{a}}$ & $0.50 \pm 0.06^{\mathrm{b}}$ & $0.53 \pm 0.06^{\mathrm{b}}$ \\
\hline Plasma LH $(\mathrm{ng} / \mathrm{ml})$ & $2 \cdot 35 \pm 0.23^{\mathrm{a}}$ & $1.26 \pm 0.08^{\mathrm{b}}$ & $1.17 \pm 0.07^{\mathrm{b}}$ \\
\hline Hypothalamic LHRH-I (ng) & $5 \cdot 35 \pm 0.50^{\mathrm{a}}$ & $4.86 \pm 0.52^{\mathrm{a}}$ & $4.19 \pm 0.34^{\mathrm{a}}$ \\
\hline
\end{tabular}

Values with different superscripts are significantly different, $P<0 \cdot 0$ I, by analysis of variance and least-significant differences.

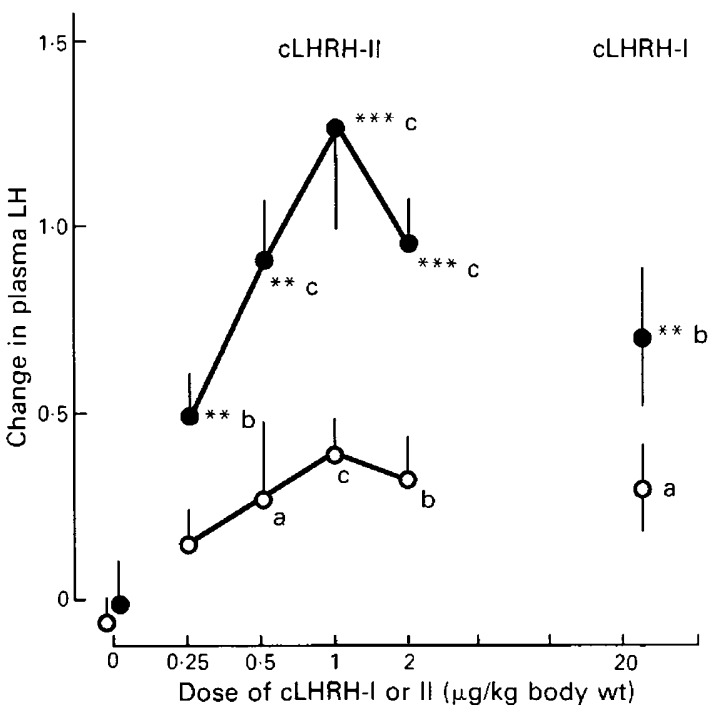

Fig. 2. Incremental changes in concentrations of plasma luteinizing hormone ( $\mathrm{LH}) 10 \mathrm{~min}$ after i.v. injections of chicken LH-releasing hormone-I and II (cLHRH-I and II) in young (28 weeks,

-) and old (105 weeks, $O)$ laying domestic hens. Values are means \pm s.e.m. $(n=8)$.

${ }^{* *} P<0.001,{ }^{* * *} P<0.001$ for comparisons between the same dose of cLHRH-I or II and ${ }^{\mathrm{a}} P<0.05,{ }^{\mathrm{b}} P<0.01,{ }^{\mathrm{c}} P<0.001$ for comparisons within age groups, between the response of the control hens injected with saline vehicle and different doses of cLHRH-J or II by analysis of variance and least-significant differences.

The increases in plasma LH after injection of all doses of LHRH-II or I were greater in young than in old laying hens (Fig. 2).

Changes in photoperiodic responses. Young hens continued laying, although at a reduced rate, after daylength was reduced from 14 to $8 \mathrm{~h}$ light/day, whereas most old hens stopped laying (Table 2). The decrease in egg production in young hens transferred to short days $(-27 \pm 11 \%)$ was similar to that in control young hens maintained on $14 \mathrm{~h}$ light/day $(-26 \pm 10 \%)$. The low rate of egg production in the control old hens maintained on $14 \mathrm{~h}$ light/day did not change significantly during the study. Reduced daylength was associated with a significant decrease in concentrations of 
plasma $\mathrm{LH}$ in young and old hens (Table 2). There was no change in egg production in young or old hens after daylength was increased from 14 to $20 \mathrm{~h}$ light/day. However, egg production decreased less $(P<0.05)$ in young hens transferred from 14 to $20 \mathrm{~h}$ light/day than in young control hens maintained on $14 \mathrm{~h}$ light/day. The concentration of plasma $\mathrm{LH}$ increased in young, but not in old, hens transferred from 14 to $20 \mathrm{~h}$ light/day (Table 2). There were no changes in concentrations of plasma $\mathrm{LH}$ in young or old control hens maintained on $14 \mathrm{~h} \mathrm{light/day.}$

Table 2. Response of the reproductive system of young ( 28 weeks) and old (105 weeks) laying hens exposed to $14 \mathrm{~h} \mathrm{light} / \mathrm{day}(14 \mathrm{~L}: 10 \mathrm{D})$ and then increased (20L:4D) or reduced daylength (8L:16D) for 28 days (means \pm s.e., $n=8$ )

\begin{tabular}{|c|c|c|c|c|}
\hline \multirow[b]{2}{*}{ Ovarian or pituitary function } & \multirow[b]{2}{*}{ Age } & \multicolumn{3}{|c|}{ Treatment } \\
\hline & & $\begin{array}{l}14 \mathrm{~L}: 10 \mathrm{D} \\
\text { to } 14 \mathrm{~L}: 10 \mathrm{D}\end{array}$ & $\begin{array}{c}14 \mathrm{~L}: 10 \mathrm{D} \\
\text { to } 8 \mathrm{~L}: 16 \mathrm{D}\end{array}$ & $\begin{array}{l}\text { l4L: } 10 \mathrm{D} \\
\text { to } 20 \mathrm{~L}: 4 \mathrm{D}\end{array}$ \\
\hline \multirow[t]{2}{*}{ Number of hens not laying } & Young & $1 / 8^{a}$ & $1 / 8^{\mathrm{a}}$ & $0 / 8^{a}$ \\
\hline & Old $^{1}$ & $2 / 8^{a}$ & $7 / 8^{+b}$ & $1 / 8^{a}$ \\
\hline \multicolumn{5}{|l|}{ Egg production (no. of eggs/hen/week) } \\
\hline Before treatment & Young & $5 \cdot 50 \pm 0 \cdot 50^{\mathrm{a}}$ & $6 \cdot 25 \pm 0 \cdot 24^{b}$ & $5 \cdot 30 \pm 0 \cdot 18^{\mathrm{a}}$ \\
\hline After treatment & Young & $4.00 \pm 0.67^{* a}$ & $4.62 \pm 0.48^{* a}$ & $4.87 \pm 0.21^{\mathrm{a}}$ \\
\hline Before treatment & Old & $3 \cdot 12 \pm 0.45^{a}$ & $3 \cdot 50 \pm 0.38^{a}$ & $3.00 \pm 0.60^{\mathrm{a}}$ \\
\hline After treatment & Old & $2 \cdot 00 \pm 0.40^{4}$ & $0.25 \pm 0.24^{* b}$ & $2 \cdot 50 \pm 0.63^{\mathrm{a}}$ \\
\hline \multirow[t]{2}{*}{ Weight of ovaries minus follicles $>8 \mathrm{~mm}(\mathrm{~g})$} & Young & $5.72 \pm 0.62^{\mathrm{a}}$ & $5.66 \pm 0.56^{\mathrm{a}}$ & $6.20 \pm 0.55^{\mathrm{a}}$ \\
\hline & Old & $6.55 \pm 1.05^{\mathrm{a}}$ & $4 \cdot 07 \pm 0.51^{\mathrm{a}}$ & $6.55 \pm 0.87^{\mathrm{a}}$ \\
\hline \multirow[t]{2}{*}{ Number of follicles $>8 \mathrm{~mm}$} & Young & $4.50 \pm 0.73^{a}$ & $3.75 \pm 0.72^{a}$ & $4 \cdot 50 \pm 0.33^{\mathrm{a}}$ \\
\hline & Old & $3 \cdot 00 \pm 0 \cdot 68^{\mathrm{a}}$ & $0.33 \pm 0.37^{\mathrm{b}}$ & $4 \cdot 13 \pm 0.64^{\mathrm{a}}$ \\
\hline \multirow[t]{2}{*}{ Oviduct weight (g) } & Young & $54.92 \pm 2 \cdot 5^{a}$ & $41 \cdot 62 \pm 5 \cdot 60^{b}$ & $52 \cdot 15 \pm 3 \cdot 12^{\mathrm{a}}$ \\
\hline & Old & $48.71 \pm 8 \cdot 8^{a}$ & $14 \cdot 15 \pm 5 \cdot 30^{b}$ & $47.63 \pm 7 \cdot 02^{a}$ \\
\hline \multicolumn{5}{|l|}{ Plasma luteinizing hormone $(\mathrm{ng} / \mathrm{ml})$} \\
\hline Before treatment & Young & $1 \cdot 98 \pm 0 \cdot 11^{\mathrm{a}}$ & $2 \cdot 50 \pm 0 \cdot 25^{b}$ & $1 \cdot 78 \pm 0 \cdot 20^{\mathrm{a}}$ \\
\hline After treatment & Young & $2 \cdot 14 \pm 0 \cdot 27^{\mathrm{a}}$ & $1 \cdot 61 \pm 0 \cdot 16^{* b}$ & $2 \cdot 36 \pm 0.23^{* a}$ \\
\hline Before treatment & Old & $1 \cdot 30 \pm 0 \cdot 12^{\mathrm{a}}$ & $1 \cdot 54 \pm 0 \cdot 11^{\mathrm{a}}$ & $1 \cdot 32 \pm 0 \cdot 08^{a}$ \\
\hline After treatment & Old & $1 \cdot 11 \pm 0 \cdot 10^{\mathrm{a}}$ & $0.97 \pm 0.14^{* b}$ & $1 \cdot 51 \pm 0 \cdot 14^{\mathrm{a}}$ \\
\hline
\end{tabular}

${ }^{1}$ The old hens had completed an induced moult 4 months previously.

Within each age group across different daylength regimens, values with different superscripts are significantly different, $P<0.05$, by analysis of variance and least-significant differences. ${ }^{+} P<0.05$ for comparison between young and old hens exposed to the same lighting patterns by Finney's $2 \times 2$ contingency tables. ${ }^{*} P<0.05$ compared with value before treatment by analysis of variance and least-significant differences.

Ovarian weights without large follicles and the numbers of large ovarian follicles did not change in young hens after an increase or decrease in daylength. The weights of oviducts in young hens were not affected by an increase in daylength, but were reduced after a decrease in daylength (Table 2). In old hens, a decrease in daylength was associated with the regression of the ovary and oviduct (Table 2). An increase in daylength did not affect the weights of ovaries or oviducts of old hens (Table 2).

\section{Evidence for the development of photorefractoriness}

Effect of short-day treatment combined with dietary restriction and return to long days on hypothalamic-pituitary-gland function in old hens. Egg production stopped and moult was induced in old hens at the end of their first laying year 4 weeks after transfer from long to short daylengths and dietary restriction. Control hens maintained on long days continued to lay. There were no significant differences in the rates of lay $(2.59 \pm 0.36$ vs. $2.64 \pm 0.4 \mathrm{eggs} / \mathrm{hen} /$ week $)$ or concentrations of plasma LH $(1.94 \pm 0.14$ vs. $2.01 \pm 0.20 \mathrm{ng} / \mathrm{ml})$ between control and experimental groups before transfer to short days. Egg production and concentrations of plasma LH were higher 
in moulted hens 6 weeks after return to long days than in unmoulted control hens (Table 3). The increase in concentrations of plasma LH after injection of 0.125 or $1 \mu \mathrm{g}$ chicken $\mathrm{LHRH}-\mathrm{II} / \mathrm{kg}$ was greater in moulted than in unmoulted hens (Table 3).

Short-day treatment and subsequent photostimulation had no significant effect on hypothalamic LHRH-I content or pituitary LH concentration (Table 3).

Two of six moulted hens and all six unmoulted control hens stopped laying after daylength was reduced from 14 to $8 \mathrm{~h}$ light/day (Table 4). This reduction in reproductive activity was reflected by a corresponding decrease in the mean rates of egg production and in concentrations of plasma $\mathbf{L H}$ (Table 4). Egg production and concentrations of plasma $\mathrm{LH}$ did not change in control moulted or unmoulted hens retained on $14 \mathrm{~h}$ light/day. An increase in daylength from 14 to $17 \mathrm{~h} \mathrm{light/day} \mathrm{was}$ associated with an increase in egg production in moulted, but not in unmoulted hens. There were no associated changes in concentrations of plasma LH (Table 4).

Hypothalamic-pituitary-gland-ovarian function in old hens after induction of ovarian regression by dietary restriction or short-day treatment. There were no differences in numbers of hens laying, rates of egg production or concentrations of plasma $\mathrm{LH}$ amongst the control and two treatment groups at the start of the study. Egg production stopped within 2 weeks of transfer from continuous light to $3 \mathrm{~h} \mathrm{light/day} \mathrm{or} \mathrm{after} \mathrm{dietary} \mathrm{restriction,} \mathrm{and} \mathrm{resumed} \mathrm{2-3} \mathrm{weeks} \mathrm{after} \mathrm{return} \mathrm{to} \mathrm{the}$ original lighting or feeding regimen (Fig. 3). The concentration of plasma $\mathrm{LH}$ decreased $(P<0 \cdot 05)$ in hens transferred from continuous light to $3 \mathrm{~h}$ light/day, but not in those subjected to dietary restriction (Fig. 3). After transfer back to continuous light, plasma $\mathrm{LH}$ increased rapidly to a peak and subsequently increased slowly to $1.91 \pm 0.14 \mathrm{ng} / \mathrm{ml}$, which was higher $(P<0.01)$ than in control hens $(1.58 \pm 0.08 \mathrm{ng} / \mathrm{ml})$, but the same as in hens which had been subjected to dietary restriction $(1.92 \pm 0.16 \mathrm{ng} / \mathrm{ml})$ (Fig. 3).

Hens transferred to short days were moulting heavily at the time they were transferred back to continuous light whereas hens subjected to a restricted diet did not begin to moult until after the dietary restriction was lifted (Fig. 3).

Four weeks after return to the original lighting or feeding regimen, the proportions of hens laying in each treatment group were not different, but were higher than in control hens (Table 5). Similarly, the rates of lay of hens in both treatment groups were higher than in the control birds (Table 5). In laying hens, the weights of the ovaries without large follicles were the same in both treatment groups, but were greater than in the control group (Table 5). The number of large follicles in the ovaries of laying hens in the two treatment groups were the same and were greater for hens subjected to the short-day treatment than in laying control birds (Table 5).

Effect of daylength on persistence of egg-laying. Egg production in hens brought back into lay for a second year by increasing the daylength from 3 to $20 \mathrm{~h} \mathrm{light/day,} \mathrm{after} \mathrm{an} \mathrm{induced} \mathrm{moult,}$ increased to a peak of 3.9-4.3 eggs/hen/week 4-9 weeks after photostimulation and decreased thereafter (Fig. 4). Egg production in hens similarly treated and transferred from 3 to $11 \mathrm{~h} \mathrm{light} /$ day increased more slowly, achieving a lower $(P<0.05)$, but more sustained, maximum between 10 and 33 weeks after photostimulation (Fig. 4). Control hens maintained on $3 \mathrm{~h} \mathrm{light/day} \mathrm{throughout}$ the study also came back into lay with a maximum rate of egg production that was less $(P<0 \cdot 05)$ than that for hens exposed to 11 or $20 \mathrm{~h} \mathrm{light/day} \mathrm{(Fig.} \mathrm{4).} \mathrm{After} 15$ weeks of photostimulation, the rate of egg production in hens exposed to $11 \mathrm{~h}$ light/day was consistently greater $(P<0 \cdot 05)$ than in those exposed to $20 \mathrm{~h} \mathrm{light/day} \mathrm{(Fig.} \mathrm{4).} \mathrm{After} 32$ weeks of photostimulation egg production in hens exposed to $20 \mathrm{~h}$ light/day decreased to that seen in control hens exposed to $3 \mathrm{~h} \mathrm{light/day,} \mathrm{while} \mathrm{egg}$ production in hens exposed to $11 \mathrm{~h}$ light/day remained significantly greater $(P<0 \cdot 05)$ (Fig. 4).

At the end of the study, after 42 weeks of photostimulation, the total number of eggs laid by hens exposed to 11 or $20 \mathrm{~h}$ light/day was not significantly different ( $109 \pm 14 \mathrm{vs} .103 \pm 9 \mathrm{eggs} / \mathrm{hen})$, but was significantly greater than the number laid by hens exposed to $3 \mathrm{~h} \mathrm{light/day}(54 \pm 8 \mathrm{eggs} /$ hen).

Egg production in old laying hens exposed to $3 \mathrm{~h}$ light/day for 40 weeks was significantly greater $(P<0 \cdot 01)$ after transfer to $20 \mathrm{~h}$ light/day than in control hens (Fig. 5a). Egg production in hens 


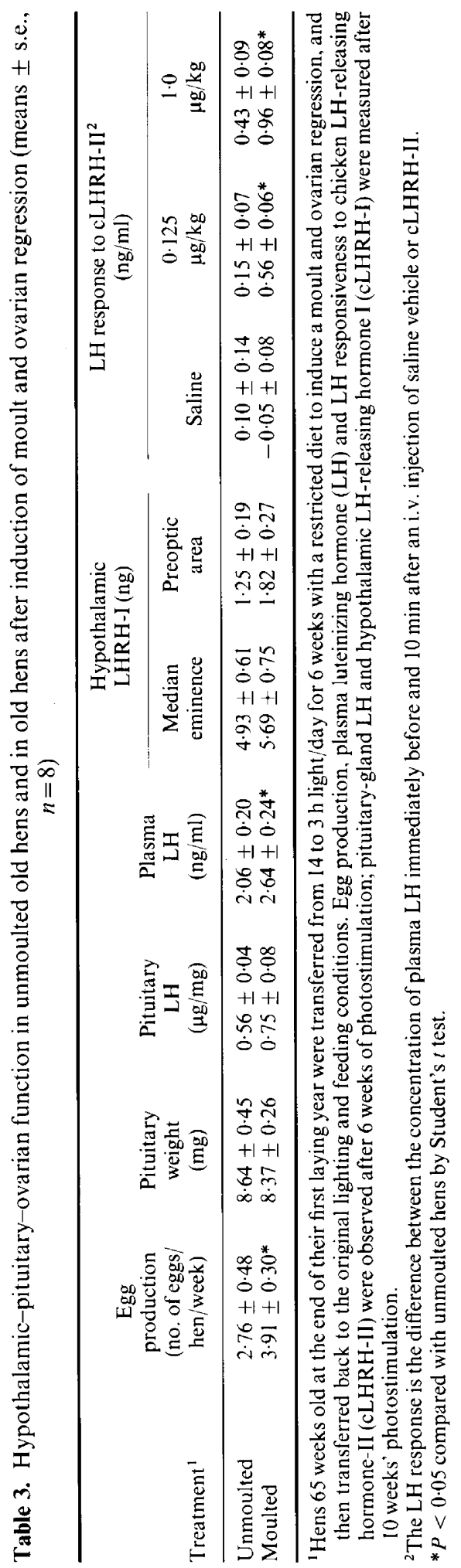


Table 4. Response of the reproductive system of old, unmoulted and moulted 71-week-old laying hens to an increase or decrease in daylength from $14 \mathrm{~h}$ light/day (14L:10D) (means \pm s.e., $n=6$ )

\begin{tabular}{|c|c|c|c|c|c|}
\hline \multirow[b]{2}{*}{$\begin{array}{l}\text { Ovarian or } \\
\text { pituitary function }\end{array}$} & \multirow[b]{2}{*}{$\begin{array}{l}\text { Reproductive } \\
\text { condition }\end{array}$} & \multicolumn{4}{|c|}{ Treatment $^{1}$} \\
\hline & & $\begin{array}{l}\text { I4L:10D } \\
\text { to } 14 \mathrm{~L}: 10 \mathrm{D}\end{array}$ & $\begin{array}{l}\text { 14L:10D } \\
\text { to 1IL:13D }\end{array}$ & $\begin{array}{l}14 \mathrm{~L}: 10 \mathrm{D} \\
\text { to } 8 \mathrm{~L}: 10 \mathrm{D}\end{array}$ & $\begin{array}{l}\text { 14L:10D } \\
\text { to } 17 \mathrm{~L}: 7 \mathrm{D}\end{array}$ \\
\hline Number of hens not laying & $\begin{array}{l}\text { Unmoulted } \\
\text { Moulted }\end{array}$ & $\begin{array}{l}1 / 6^{\mathrm{a}} \\
0 / 6^{\mathrm{a}}\end{array}$ & $\begin{array}{l}3 / 6^{\mathrm{a}} \\
1 / 6^{\mathrm{a}}\end{array}$ & $\begin{array}{l}6 / 6^{\mathrm{b}} \\
2 / 6^{\mathrm{b}+}\end{array}$ & $\begin{array}{l}0 / 6^{\mathrm{a}} \\
0 / 6^{\mathrm{a}}\end{array}$ \\
\hline \multicolumn{6}{|c|}{ Egg production (no. of eggs/hen/week) } \\
\hline $\begin{array}{l}\text { Before treatment } \\
\text { After treatment } \\
\text { Before treatment } \\
\text { After treatment }\end{array}$ & $\begin{array}{l}\text { Unmoulted } \\
\text { Unmoulted } \\
\text { Moulted } \\
\text { Moulted }\end{array}$ & $\begin{array}{l}3 \cdot 16 \pm 0 \cdot 54^{\mathrm{a}} \\
2 \cdot 33 \pm 0 \cdot 99^{\mathrm{ab}} \\
4 \cdot 00 \pm 0 \cdot 93^{\mathrm{a}} \\
4 \cdot 33 \pm 0 \cdot 49^{\mathrm{ab}}\end{array}$ & $\begin{array}{l}3 \cdot 00 \pm 0.51^{\mathrm{a}} \\
1 \cdot 36 \pm 0.42^{\mathrm{b} *} \\
3 \cdot 34 \pm 0.40^{\mathrm{a}} \\
3 \cdot 06 \pm 0.27^{\mathrm{b}}\end{array}$ & $\begin{array}{l}2 \cdot 50 \pm 0 \cdot 62^{\mathrm{a}} \\
0 \cdot 00 \pm 0 \cdot 00^{\mathrm{c} * * *} \\
3 \cdot 30 \pm 0 \cdot 56^{\mathrm{a}} \\
1 \cdot 33 \pm 0 \cdot 88^{* \mathrm{c}}\end{array}$ & $\begin{array}{l}3 \cdot 50 \pm 0.64^{\mathrm{a}} \\
4 \cdot 00 \pm 0 \cdot 49^{\mathrm{a}} \\
3 \cdot 62 \pm 0 \cdot 34^{\mathrm{a}} \\
5 \cdot 00 \pm 0 \cdot 32^{* a}\end{array}$ \\
\hline \multicolumn{6}{|c|}{ Plasma luteinizing hormone (ng/ml) } \\
\hline $\begin{array}{l}\text { Before treatment } \\
\text { After treatment } \\
\text { Before treatment } \\
\text { After treatment }\end{array}$ & $\begin{array}{l}\text { Unmoulted } \\
\text { Unmoulted } \\
\text { Moulted } \\
\text { Moulted }\end{array}$ & $\begin{array}{l}2 \cdot 10 \pm 0 \cdot 08^{\mathrm{a}} \\
2 \cdot 13 \pm 0 \cdot 11^{\mathrm{a}} \\
2 \cdot 44 \pm 0 \cdot 16^{\mathrm{a}} \\
2 \cdot 31 \pm 0 \cdot 11^{\mathrm{a}}\end{array}$ & $\begin{array}{l}1 \cdot 95 \pm 0 \cdot 17^{\mathrm{a}} \\
2 \cdot 13 \pm 0 \cdot 14^{\mathrm{a}} \\
2 \cdot 34 \pm 0 \cdot 28^{\mathrm{a}} \\
2 \cdot 19 \pm 0 \cdot 14^{\mathrm{a}}\end{array}$ & $\begin{array}{l}2 \cdot 03 \pm 0 \cdot 24^{\mathrm{a}} \\
1 \cdot 28 \pm 0 \cdot 14^{* \mathrm{~b}} \\
2 \cdot 49 \pm 0 \cdot 25^{\mathrm{a}} \\
1 \cdot 74 \pm 0 \cdot 18^{* \mathrm{~b}}\end{array}$ & $\begin{array}{l}2 \cdot 05 \pm 0 \cdot 13^{\mathrm{a}} \\
2 \cdot 12 \pm 0 \cdot 16^{\mathrm{a}} \\
2 \cdot 31 \pm 0 \cdot 11^{\mathrm{a}} \\
2 \cdot 56 \pm 0 \cdot 14^{\mathrm{a}}\end{array}$ \\
\hline
\end{tabular}

${ }^{1}$ The hens were moulted by reducing the daylength from 14 to $3 \mathrm{~h}$ light/day and restricting food intake for 6 weeks before return to $14 \mathrm{~h} \mathrm{light/day;} \mathrm{after} \mathrm{a} \mathrm{further} 4$ weeks they were transferred in groups of six to $8,11,14$ or $17 \mathrm{~h}$ light/day with control groups of laying unmoulted hens. Observations were made 6 weeks later.

For comparisons of unmoulted or moulted hens across different daylength regimens, values with different superscripts are significantly different, $P<0 \cdot 05$, by Finney`s $2 \times 2$ contingency tables for number of hens laying, and by analysis of variance and least-significant differences for the remaining data.

${ }^{* * *} P<0.001,{ }^{*} P<0.05$ for comparisons between unmoulted and moulted hens exposed to the same daylength regimen by analysis of variance and least-significant differences.

${ }^{+} P<0.05$ for comparison between unmoulted and moulted hens exposed to the same daylength regimen, by Finney's $2 \times 2$ contingency tables.

similarly exposed to $11 \mathrm{~h} \mathrm{light/day} \mathrm{for} 40$ weeks was also significantly greater $(P<0.05)$ than in control hens after daylength was increased to $20 \mathrm{~h}$ light/day, although only for a transitory period of 5 weeks (Fig. 5b). Old hens exposed to $20 \mathrm{~h} \mathrm{light/day} \mathrm{for} 46$ weeks stopped laying after transfer to $3 \mathrm{~h}$ light/day (Fig. 5c).

\section{Discussion}

These findings show that reduced gonadotroph function is a major factor underlying reduced egglaying in hens exposed to a stimulatory daylength for a prolonged period. This is indicated by the reduction in concentrations of plasma and pituitary-gland LH and the loss of pituitary-gland responsiveness to chicken LHRH-I and II at the end of the first laying year (Table 1, Fig. 2). The observation that, in laying hens, LH is released more readily by chicken LHRH-II than by LHRHI confirms an earlier study (Sharp et al., 1987). The different responses to the two releasing hormones are unlikely to be physiologically important since LHRH-I, rather than LHRH-II, is thought to be directly involved in stimulating $\mathrm{LH}$ release at the level of the anterior pituitary gland (Sharp et al., 1990a, b). A similar loss of pituitary-gland responsiveness to LHRH has been observed in ageing rats with persistent oestrus, although this was not associated with a reduction in concentrations of plasma or pituitary LH (Watkins et al., 1975; Smith et al., 1982). It appears that, in chickens, as in rats and some strains of mice, the pacemaker for reduced reproductive function is within the neuroendocrine system (review, vom Saal \& Finch, 1988). This contrasts with primates, including man, and some strains of mice, in which ovulatory failure is due to the absence of a critical number of oocytes within the ovary (Vom Saal \& Finch, 1988). Oocyte exhaustion is unlikely to play any role in reduced egg-laying in one- or two-year-old hens, since their ovaries contain large numbers of oocytes (Pearl \& Schoppe, 1921; Gilbert, 1972). Furthermore, oocyte exhaustion 

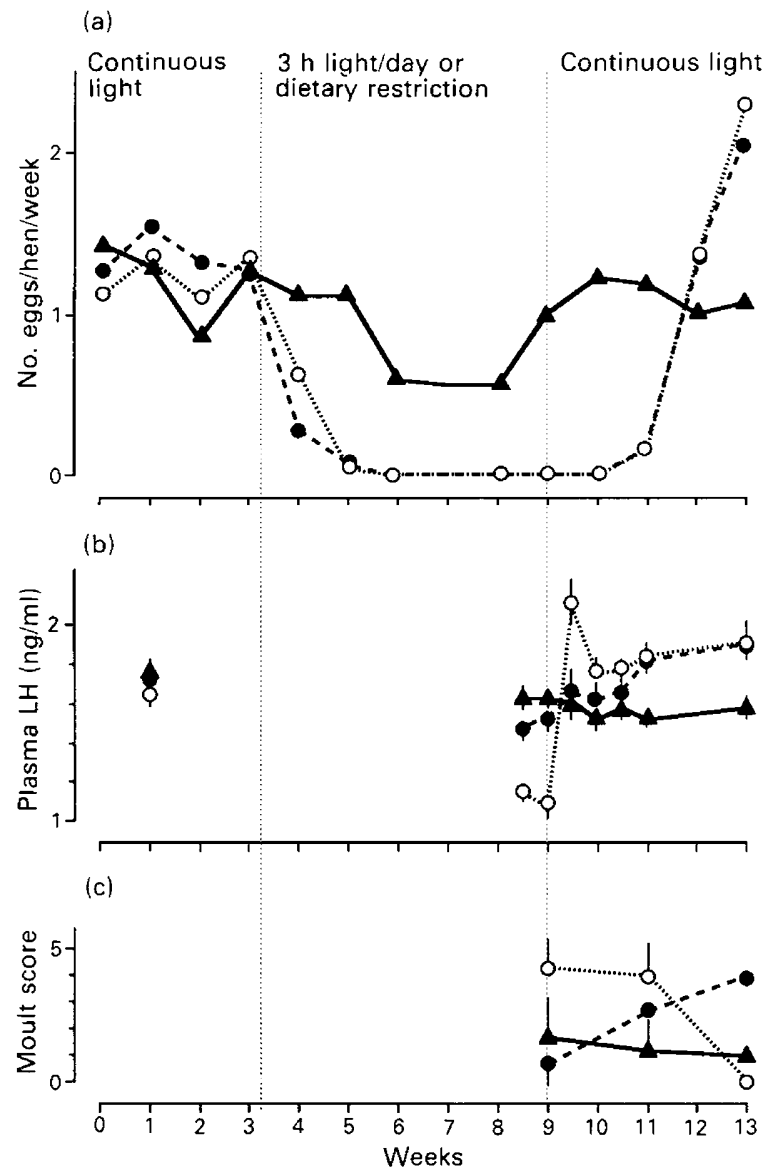

Fig. 3. Changes in (a) egg production, (b) concentrations of plasma LH and (c) moult score (0, no moult to 5, full moult) in domestic hens at the end of a second laying year during and after an interruption in egg production produced by either reducing daylength from continuous light to $3 \mathrm{~h}$ light/day $(O)(n=18)$, or dietary restriction $(\bullet)(n=26)$. Control hens $(\Delta)(n=23)$ were maintained on continuous light throughout the study.

only occurs in primates and some mice towards the end of their natural life-span (Vom Saal \& Finch, 1988). Since hens live for at least 7-8 years and do not show a substantial reduction in seasonal egg production during successive years until they are about 4 years old (Brody et al., 1938), oocyte exhaustion is unlikely to contribute to reduced egg production in 1- or 2-year-old hens. However, the possibility that changes in ovarian responsiveness to gonadotrophins contribute to reduced ovulation rate in hens ex posed to long daylengths for several months cannot be ruled out. It has been found that the ability of LHRH and LH to induce ovulation (Etches et al., 1983; Moudgal \& Razdan, 1985) and of LH to induce adenylyl cyclase activity in the granulosa cells of the largest ovarian follicles (Johnson et al., 1986) is greater in hens with a high rate of egg production than in hens with a low rate of egg production. Whether this apparent reduction in ovarian responsiveness is a function of ovarian ageing or secondary to a reduction in concentrations of circulating gonadotrophins remains to be established.

A decrease in ovarian responsiveness to gonadotrophins may explain, in part, the smaller number of ovarian follicles recruited into the follicular hierarchy of older hens (Table 1). Additionally, a reduction in gonadotrophic support reflected by depressed circulating concentrations of $\mathrm{LH}$ 


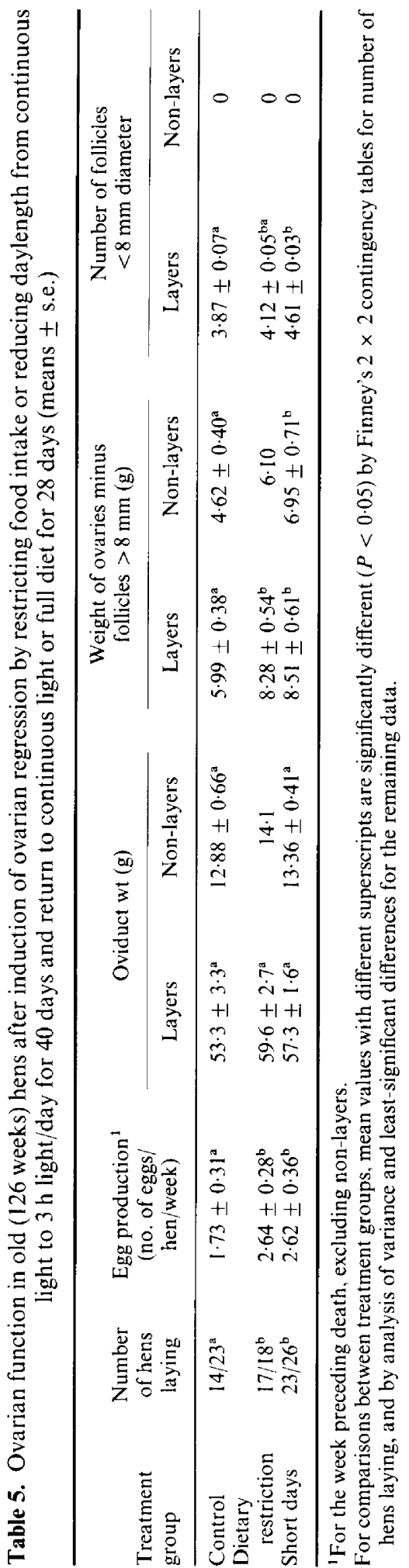




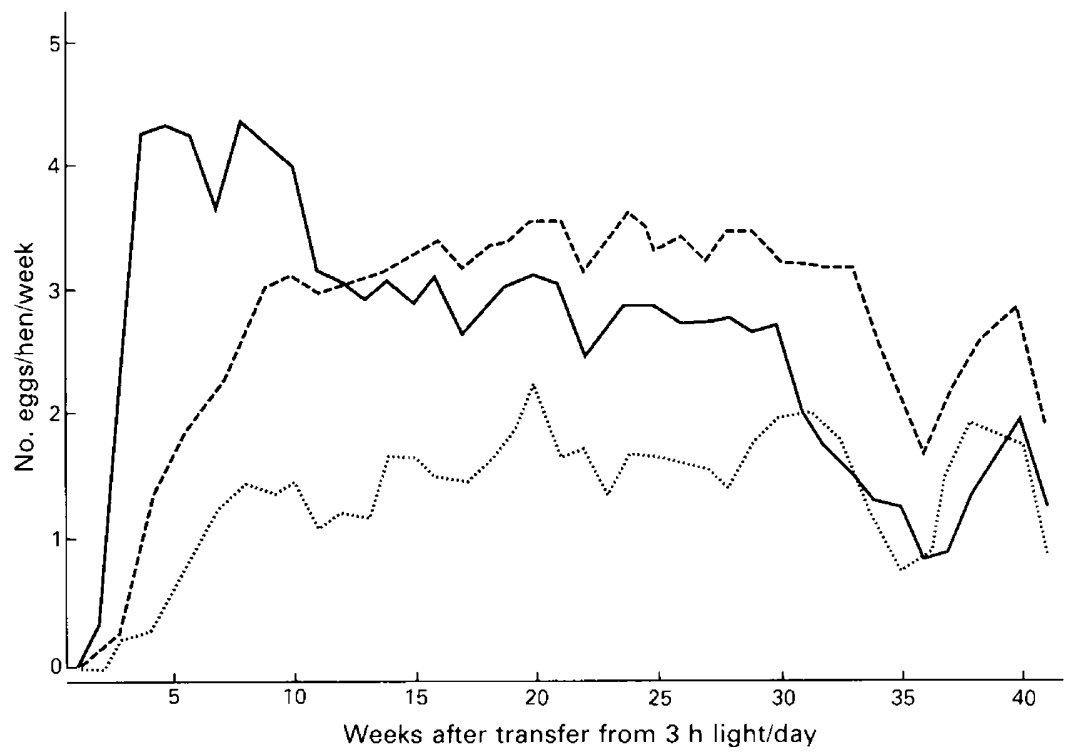

Fig. 4. Egg production in three groups of domestic hens $(n=48)$ previously subjected to an induced moult at the end of their first laying year ( 74 weeks), which involved transferring them from 16 to $3 \mathrm{~h}$ light/day for 6 weeks. The hens were brought back into lay by increasing the daylength to $11(----)$ or $20 \mathrm{~h}$ ( - ) light/day; the control group was retained on $3 \mathrm{~h}$ light/day $(\cdots \cdots)$.

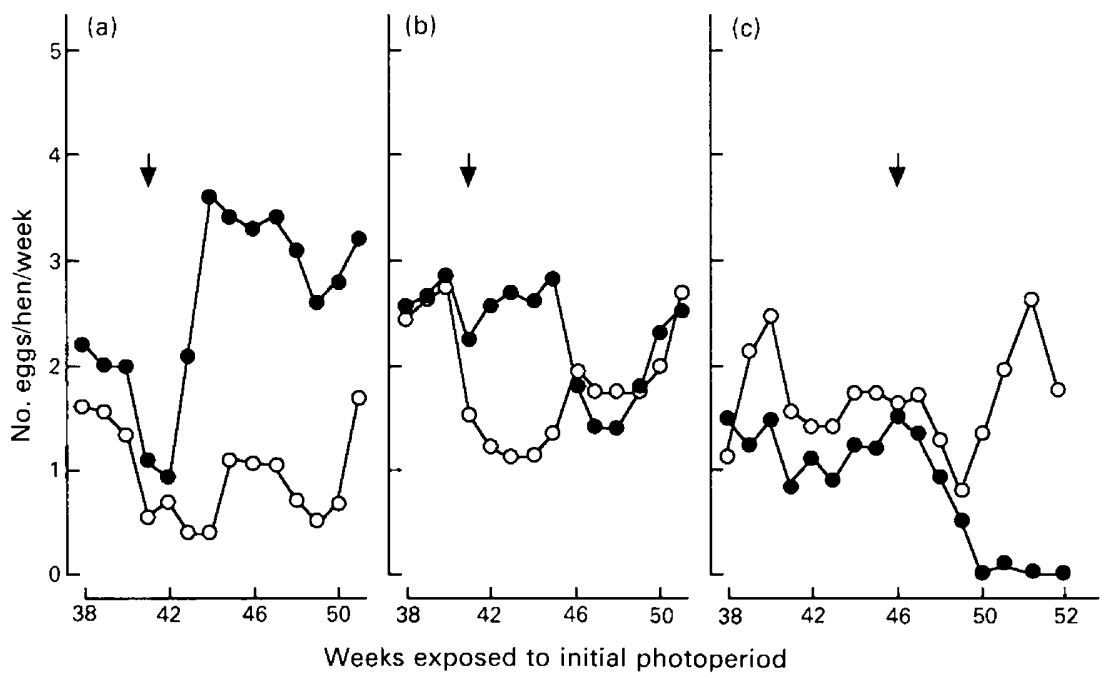

Fig. 5. Egg production in domestic hens subjected to a change in daylength ( $)$. Hens were transferred during their second laying year ( $\downarrow$ ) from (a) 3 to $20 \mathrm{~h} \mathrm{light/day,} \mathrm{(b)} 11$ to $20 \mathrm{~h} \mathrm{light/}$ day or (c) 20 to $3 \mathrm{~h}$ light/day; the control hens $(O)$ were retained on the original photoperiods $(n=19-24)$. 
(Table 1) may also play a role. The reduced recruitment into the ovarian follicular hierarchy eventually gives way to complete ovarian regression.

The observation that old hens recover from this condition and lay eggs for several weeks before going out of lay again (Fig. 1) has not been reported previously. The mechanism involved remains to be investigated, but could involve cyclic changes in the responsiveness of the anterior pituitary gland to the inhibitory action of ovarian secretions or recovery of hypothalamic sensitivity to stimulatory environmental factors. It is possible that selection for egg production in commercial hens results in a daylength-independent increase in reproductive function. The switch between laying and non-laying may therefore represent periods when the overt expression of photorefractoriness, egg production, is obscured by the effects of this daylength-independent drive on reproductive activity. This situation may be similar to that observed in semidomesticated mallard ducks, in which photorefractoriness is not maintained indefinitely by exposure to long days (Storey \& Nicholls, 1978).

The reduction in gonadotroph function associated with decreased egg laying could be partly a function of age per se, resulting in a loss of LHRH receptors, an uncoupling of LHRH receptors from their signal transduction pathways or impairment in the function of these pathways. Equally, reduced gonadotroph function may be secondary to a reduction in LHRH release from the hypothalamus resulting in reduced LH release and synthesis (Starzec et al, 1986). The failure to demonstrate a consistent change in hypothalamic LHRH-I content in relation to decreased egg production (Table 1) provides no evidence for or against an involvement of the hypothalamus in decreased gonadotrophin secretion and release. This is because steady-state levels of LHRH do not reflect LHRH release. This view is supported by observations in old and young female rats in which no differences were observed in hypothalamic LHRH content, although reproductive function was depressed in the older animals (Steger et al., 1979; Rubin et al., 1985). However, in rats, measurements of $\mathrm{K}^{+}$-stimulated release of GnRH (Huang et al., 1990) or of LHRH release using push-pull cannulae (Rubin \& Bridges, 1989) show that hypothalamic LHRH output is reduced in ageing females. A similar reduction in LHRH output may therefore explain reduced gonadotroph function in hens with reduced rates of egg production.

The observations on the photoperiodic responses of young and old hens are consistent with a reduction in the function of LHRH neurones in old hens. Such a reduction would explain why egg production decreased more rapidly in old than in young hens after removing the stimulatory effects of long days (Table 2). Conversely, the observation that plasma LH increased in young, but not in old, hens after further increasing daylength from 14 to $20 \mathrm{~h}$ light/day is also consistent with a reduction in function of $\mathrm{LHRH}$ neurones in old hens.

The decrease in egg production in young control hens maintained on $14 \mathrm{~h}$ light/day which was not associated with a decrease in LH (Table 2) probably reflects the way in which the yolk produced by the liver is 'packaged' into fewer larger eggs after the initial peak in photoinduced egg production (Williams \& Sharp, 1978a). The mechanism involved in this change in ovarian follicular structure is unknown, but does not seem to reflect a decrease in hypothalamic-pituitary-gland function, since total yolk production is not reduced (Williams \& Sharp, 1978a).

A reduction in the function of LHRH neurones in 1- or 2-year-old hens exposed continuously to long days is more likely to be due to the development of photorefractoriness, for reasons given in the Introduction, than to somatic senescence, as seen in rats (Vom Saal \& Finch, 1988). Thus, plasma LH concentrations, pituitary gland responsiveness to LHRH and egg production were increased in old laying hens after transfer to short days for 6 weeks and subsequent return to long days (Tables 3 and 5). This enhanced reproductive activity may be a consequence of the dissipation of photorefractoriness by exposure to short days. This view is further supported by observations on the photoperiodic responses of moulted and unmoulted hens in which treatment with short days to induce a moult appeared to reinstate sensitivity to increased photoperiod. Thus, after transfer from long to short days, the fall in egg production observed in moulted hens was less than that in unmoulted control birds. Conversely, egg production further increased in moulted hens, 
but not in unmoulted control birds, when daylength was increased from 14 to $17 \mathrm{~h}$ light/day (Table 4).

The finding that reproductive function improved in old hens after a moult and ovarian regression were induced by reducing food intake without decreasing daylength (Fig. 3) suggests that dietary restriction per se may dissipate photorefractoriness. Since body weight is a critical factor in determining the rate of egg-laying in broiler breeders (McDaniel et al., 1981), it is possible that the loss of body weight associated with induced moult induces neuroendocrine changes which mimic those induced by exposure to short days. Another possibility is suggested by the observation that old hens characteristically lay eggs sporadically (Fig. 1b). After the induction of moult by any means, these cycles of egg-laying are initially synchronized. At the beginning of such a cycle, when egg-laying starts, it is possible that hypothalamic-gonadotroph function may be transiently enhanced following the reduction in circulating ovarian hormones during the preceding period of ovarian regression.

The enhanced persistence of lay seen in hens photostimulated into a second year of egg production by transfer to a marginally stimulatory 11 -h daylength is consistent with what is known about the mechanism underlying the development of photorefractoriness (Nicholls et al., 1988). The 11-h daylength seems to be sufficiently stimulatory to enhance reproductive function, but not to drive the hens towards photorefractoriness as rapidly as exposure to $20 \mathrm{~h} \mathrm{light/day.} \mathrm{This} \mathrm{is} \mathrm{indicated} \mathrm{by}$ the transitory increase in egg production, compared with control hens, after transfer from 11 to $20 \mathrm{~h} \mathrm{light/day.} \mathrm{The} \mathrm{large} \mathrm{and} \mathrm{sustained} \mathrm{increase} \mathrm{in} \mathrm{egg} \mathrm{production} \mathrm{seen} \mathrm{in} \mathrm{hens} \mathrm{of} \mathrm{the} \mathrm{same} \mathrm{age}$ transferred from 3 to $20 \mathrm{~h}$ light/day shows the response of the fully photosensitive hypothalamic pituitary-gland-ovarian axis to photostimulation.

In conclusion, these experiments provide evidence that the poor rate of egg-laying observed in domestic hens after exposure to continuous long days for several months may be due, in part, to the development of photorefractoriness.

This work was supported by a commission from the Ministry of Agriculture, Food and Fisheries. We thank S. Anderson, G. Main and R. Talbot for assistance with the conduct of the experiments.

\section{References}

Brody, S., Funk, E.M. \& Kempster, H.L. (1938) Growth and development. XLIV. Energetic efficiency of egg production and the influence of live weight thereon. University of Missouri, College of Agriculture, Research Bulletin No. 278. Columbia, MO, USA.

Dunn, I.C. \& Sharp, P.J. (1990) Photoperiodic requirements for $\mathrm{LH}$ release in juvenile broiler and egglaying strains of domestic chickens fed ad libitum or restricted diets. J. Reprod. Fert. 90, 329-335.

Etches, R.J., MacGregor, H.E., Morris, T.F. \& Williams, J.B. (1983) Follicular growth and maturation in the domestic hen (Gallus domesticus). J. Reprod. Fert. 67, 351-358.

Gilbert, A.B. (1972) The activity of the ovary in relation to egg production. In Egg Formation and Production, pp. 3-21. Eds B. M. Freeman \& P. E. Lake. British Poultry Science, Edinburgh, UK.

Huang, C., Pu, H.-F., Huang, C.-Y., Lui, J.-Y., Yao, H.C., Tung, Y.-F. \& Wang, P.S. (1990) Age-related differences in the release of luteinizing hormone and gonadotropin-releasing hormone in ovariectomized rats. Neuroendocrinology 52, $127-132$.

Johnson, P.A., Dickerman, R.W. \& Bahr, J.M. (1986) Decreased granulosa cell luteinizing hormone, sensitivity and altered thecal estradiol concentrations in the aging hen Gallus domesticus. Biol. Reprod. 35, 641- 646

Lal, P., Sharp, P.J., Dunn, I.C. \& Talbot, R.T. (1990) Absence of an effect of naloxone, an opioid antagonist, on luteinizing hormone release in vivo and luteinizing hormone-releasing hormone-I release in vitro in intact, castrated, and food restricted cockerels. Gen. Comp. Endocr. 77, 239-245.

McDaniel, G.R., Brake, J. \& Bushong, R.D. (1981) Factors affecting broiler breeder performance. 1. Relationship of daily feed intake level to reproductive performance of pullets. Poult. Sci. 60, 307-312.

Moudgal, R.P. \& Razdan, M.N. (1985) Induction of ovulation in vitro in the hen: dependency of the response to LH on age and rate of lay. J. Endocr. 106, 67-69.

Nicholls, T.J., Goldsmith, A.R. \& Dawson, A. (1988) Photorefractoriness in birds in comparison with mammals. Physiol. Rev. 68, 133-176.

Pearl, R. \& Schoppe, W.F. (1921) Studies on the physiology of reproduction in the domestic fowl. XVIII. Further observations on the anatomical basis of fecundity. J. exp. Zool. 34, 101-118. 
Rubin, B.S. \& Bridges, R.S. (1989) Alterations in luteinizing hormone-releasing hormone release from the mediobasal hypothalamus of ovariectomized, steroid-primed middle-aged rats as measured by pushpull perifusion. Neuroendocrinology 49, 225-232.

Rubin, B.S., Elkind-Hirsch, K. \& Bridges, R.S. (1985) Hypothalamic LHRH in ageing rats: effects of ovariectomy and steroid replacement. Neurobiol. Aging 7, 45-48.

Sharp, P.J. (1983) Hypothalamic control of gonadotrophin secretion in birds. In Progress in Nonmammalian Brain Research, vol. III, pp. 123-176. Eds G. Nistico \& L. Bolis. CRC Press, Boca Raton, FL, USA.

Sharp, P.J. (1984) Seasonal breeding and sexual maturation. In Reproductive Biology of Poultry, pp. 203-218. Eds F. J. Cunningham, P. E. Lake \& D. Hewitt. British Poultry Science, Longman Group, Harlow, UK.

Sharp, P.J. (1988) Lighting patterns and persistency of lay. In Science and the Poultry Industry, pp. 10-11. Ed. J. Hardcastle. Agricultural and Food Research Council, London.

Sharp, P.J., Dunn, I.C. \& Talbot, R.T. (1987) Sex differences in the LH responses to chicken LHRH-I and II in the domestic fowl. J. Endocr. 115, 323-331.

Sharp, P.J., Talbot, R.T., Main, G.M., Dunn, I.C., Fraser, H.M. \& Huskisson, N.S. (1990a) Physiological roles of chicken LHRH-I and II in the control of gonadotrophin release in the domestic chicken. $J$ Endocr. 124, 291-299.

Sharp, P.J., Dunn, I.C., Main, G.M., Sterling, R.J. \& Talbot, R.T. (1990b) Gonadotropin-releasing hormones: distribution and function. In Endocrinology of Birds: Molecular to Behavioural, pp. 31-42. Eds M. Wada, S. Ishii \& C. G. Scanes. Japan Sci. Soc. Press, Springer-Verlag, Tokyo/Berlin.

Smith, W.A., Cooper, R.L. \& Conn, P.M. (1982) Altered pituitary responsiveness to gonadotropin-releasing hormone in middle-aged rats with 4-day estrous cycles. Endocrinology 111, 1843-1848.

Starzec, A., Counis, R. \& Jutisz, M. (1986) Gonadotrophin-releasing hormone stimulates the synthesis of the polypeptide chains of luteinizing hormone. Endocrinology 119, 561-564.
Steger, R.W., Huang, H.H. \& Meites, J. (1979) Relation of aging to hypothalamic LHRH content and serum gonadal steroids in female rats. Proc. Soc. exp. Biol. Med. 161, 251-254.

Storey, C.R. \& Nicholls, J. (1978) Observations on the regulation of sexual quiescence in juvenile and adult male mallards (Anas platyrhyncos). J. Zool. 184, $181 \cdot 186$.

Tanabe, Y., Nakamura, T., Tanase, H. \& Doi, O. (1981) Comparisons of plasma $\mathrm{LH}$, progesterone, testosterone and estradiol concentrations in male and female chickens (Gallus domesticus) from 28 to 1141 days of age. Endocr. jap. 28, 605-613.

Vom Saal, F.S. \& Finch, C.E. (1988) Reproductive senescence: phenomena and mechanisms in mammals and selected vertebrates. In The Physiology of Reproduction, pp. 2351 2400. Eds E. Knobil \& J. Neill. Raven Press, New York.

Wakeling, D. (1985) Practical aspects of inducing a moult in commercial laying fowl. In Poultry Section Quarterly Journal B, vol. 147, pp.9-23. ADAS, Ministry of Agriculture Fisheries \& Food, Wolverhampton, UK

Waddington, D., Perry, M.M., Gilbert, A.B. \& Hardie, M.A. (1985) Follicular growth and atresia in the ovaries of hens (Gallus domesticus) with diminished egg production rates. $J$. Reprod. Fert. 74, 399-405.

Watkins, B., Meites, J. \& Riegle, G. (1975) Age-related changes in pituitary responsiveness to LHRH in the female rat. Endocrinology 97, 543 548 .

Whetham, E.O. (1933) Factors modifying egg production with special reference to seasonal changes. $J$. Agric. Sci. (Camb.) 23, 383-412.

Williams, J.B. \& Sharp, P.J. (1978a) Ovarian mor. phology and rates of ovarian follicular development in laying broiler breeders and commercial egg producing hens. Br. Poult. Sci. 19, 387-395.

Williams, J.B. \& Sharp, P.J. (1978b) Age-dependent changes in the hypothalamo pituitary-ovarian axis of the laying hen. J. Reprod. Fert. 53, 141-146.

Zakaria, A.H., Miyaki, T. \& Imai, K. (1983) The effect of aging on the ovarian follicular growth in laying hens. Poult. Sci. 62, 670.674.

Received 24 December 1990 